\title{
International Education Cooperation under the Background of Belt and Road Initiative
}

\author{
Xiaoling Fang \\ Tibetan Academy of Social Science \\ Lhasa, Tibet, China
}

\begin{abstract}
What the "Belt and Road Initiative" advocates is to build a world featuring permanent peace, universal security, common prosperity, openness, inclusiveness, green and beautifulness, and all countries and regions are required to promote the reform and development through opening up and carry out multi-level and multi-field educational exchanges and cooperation and provide talents for more wider economic cooperation and cultural exchanges. International education cooperation shall be conducted under the principles such as resource integration, advancing what we can share and letting what we cannot do go, mutual respects and benefits, and focused on international cooperation in higher education and vocational education, supported by preparation for entering the higher education, and multiple strengths such as governments, schools, non-governmental organizations as well as enterprises shall be encouraged to participate in the cooperation, besides, a quality guarantee system shall be set up to overall enhance the international education cooperation level on the background of the Belt and Road Initiative.
\end{abstract}

Keywords-Belt and Road Initiative; international education cooperation

\section{INTRODUCTION}

Several years ago, doubts were still held internationally to the Belt and Road Initiative that China advocated, however, with the time going as well as the presentation and improvement made by Chinese government, the doubts have been gone gradually. In the past three years, it has attracted more than 100 countries and international organizations to participate, of which, over 40 have concluded cooperation proposals with China, and a broad consensus on international cooperation has come into being [1]. The cooperation that has been started is mainly focused on the strategic connections between countries, economic and trade exchanges, two-way investment, China-Europe freight trains as well as green, healthy, intellectual and peaceful cultural exchanges, compared to which, the international education cooperation is falling behind.

\section{BELT AND ROAD INITIATIVE FITTING IN WITH INTERNATIONAL EDUCATION COOPERATION IN CONCEPT}

Belt and Road Initiative that China advocates is to build a community of shared future for mankind, aiming to create a world featuring permanent peace, universal security, common prosperity, openness, inclusiveness, green and beautifulness through negotiation, exchanges and cooperation. Different countries and regions own different histories and corresponding cultural concepts, it is just the diversity of cultures that make the world rich and colorful, which is a drive for the co-development of the mankind. The Belt and Road Initiative is an embodiment of Chinese tradition "Co-existing but diverse", and what it stresses are the connections, cooperation and win-win among different countries, which requires that when pursuing the benefits of its own, a country should honor what the other countries need.

Most hold the opinions that the Belt and Road Initiative should be centered on the economic cooperation, actually it is a lopsided view, any economic exchange and cooperation cannot be separated from the direct or indirect communication between the people in different countries and regions, it has to get involved in the cultural exchanges. It can be said literally that as a heart to heart communication method, cultural exchange is a precondition for any other type of exchange and cooperation. Then What is the one that promotes the international economic cooperation and cultural exchange? It is the international education cooperation. Because any kind of international cooperation cannot be separated from the people to people communication, whether oral and written, all need language service for the countries that have established cooperation. It is just a part of it, with the wide development of international cooperation, it will form a large gap in the supply of compound talents, in addition to language skills, the compound talents shall own knowledge relative to economy, trade, law, engineering technology or politics, culture and history among different countries and regions, who are urgently needed for the economic cooperation and cultural exchange, however, it will be difficult to achieve only relying on the domestic education of one country, so the international education cooperation becomes much more important.

Just like what Chinese president $\mathrm{Xi}$ Jinping said at a meeting of the Political Bureau of the Central Committee held in 2016, to participate in global governance will need a large number of professionals who are familiar with state policies and situations, owning a global perspective, proficient in foreign languages, international rules and in international negotiations. At a state level, China has listed the internalized education into the short term development program, pointing out clearly that we should persist in 
promoting the reform and development through opening up and carrying out multi-level and multi-field educational exchanges and cooperation so as to enhance the internationalized education level. The international education cooperation needs more and more countries and regions to clearly understand the urgency of the issue, and actual measures shall be taken to promote the international education of their own, only through multiple cooperation can the international education in different countries reach goals as scheduled so as to provide talents for wider international economic cooperation and cultural exchange.

\section{PRINCIPLES AND KEY POINTS FOR INTERNATIONAL EDUCATION COOPERATION}

Resource integration: Different countries and regions have advantageous educational resources with different features, and the international education cooperation should value the leading role of predominant resources in the countries, learning what is advanced and overcome what is deficient so as to enhance the educational levels of the countries concerned. The most significant step for the educational cooperation is the flow of teacher resources among the countries, which drive the international flows of different teaching ideas and methods. So the resource integration not only gets involved in facilities and personnel visible, it also promotes the cultural exchanges invisible. All countries concerned shall insist on the resources sharing and information symmetry in the cooperation, and adequate information shall be provided by and between the participants with the mutual awareness stressed, removing any uncertainty in cooperation, and carrying out the specific plans for the resource integration via the symmetrical information exchanges.

Advancing what we can share and letting what we cannot do go: the international education cooperation will integrate the educational resources from different countries and regions, however, that does not mean all develop in the same direction. Each country and region has different histories, cultures and traditional education of its own, which is the starting point and key necessary for cooperation and a drive for a long term cooperation. With the features of their own kept, the countries concerned should set a common goal, that is, the education cooperation shall aim to cultivate international talents who are competent for all kinds of economic cooperation and cultural exchanges. In order to follow the principle, the countries concerned shall establish rules, systems, principles, decision-making procedures and code of behaviors for the international education cooperation, which are expected to promote the cooperation and exchange, supervise and honor each and restrict the participants from outside.

Mutual respects and benefits: The countries or regions that have established the international educational cooperation have the development needs of their own. Based on the different cooperation goals and facing the dilemma and interference in domestic issues such as ethnics and religion, only respecting the demands in all aspects can well advance the cooperation. And the countries or regions may select the cooperative objects and modes as the case may be, avoiding cultural violations and so on. During the international education cooperation, relevant interests and expected benefits arising out of the cooperation between the participants should be fully considered, of which, the expected benefits include long-term interests, medium-term and short-term interests as well as economic interests, political interests and cultural interests and security interests brought by the spread.

The key point of international education cooperation should be set to the higher education. Abraham Flexner, an American educator, ever showed his opinions about the higher education, which is worthy of deep thought up to now, in his opinion, there were no other institutions created that could be compared with universities according to the wisdom of mankind, as one of the educational undertakings, the universities shall be close to the real world and promote the society to adopt wise actions according to the strength and reputation[2]. Up to now, under the background of Belt and Road Initiative, more and more countries and regions along the Silk Road have entered the cooperative tide, which is just the real world that the universities have to face.

\section{SPECIFIC METHODS FOR INTERNATIONAL EDUCATION COOPERATION}

The international education cooperation where students flow among different countries and regions refers to the international cooperation in higher education and vocational education, and the international education cooperation can be carried out for high school students who are ready for international study at home.

\section{A. Cooperation in Higher Education}

The cooperation in higher education is a key part for the international education cooperation, and a lot of countries and regions have owned experience in the long term foreign education cooperation. For example, as the largest neighboring countries in Northeast Asia, China and Russia have established similar cooperation and exchanges, especially the northeast of China such as Heilongjinag province standing at the border between China and Russia, has the highest number of Sino-Russia education cooperation, and it is also the drive to further the Sino-Russia education cooperation under the background of Belt and Road Initiative. After the establishment of the WTO in 1995, the international education cooperation was launched one another. However, most of the internationalization and marketing of most of the international education were over stressed in commerce, but ignoring co-owning of the higher education. Early in 2005, United Nations Educational, Scientific, and Cultural Organization (UNESCO) and Organization for Economic Co-operation and Development (OECD) ever pointed out in the Guidelines for Quality Provision in Cross-border Higher Education, the focus for the quality provision in cross-border higher education is that the parties concerned should shoulder the joint responsibilities for the co-owning.[3] Therefore, under the background of Belt and Road Initiative, in order to further the international higher education cooperation, we should pay more attentions to the co-owning, valuing the 
positive effect of higher education talents on the codevelopment of the mankind and avoiding neglecting the lofty goal for the international cooperation in higher education in the commercial competition.

During the international cooperation in higher education, the cooperation in teaching and research should be started at the same time, for example, In 2014, the Ministry of Education of China released an "International Cooperation Joint Lab Program", which, relying on a high level technological innovation platforms and colleges and universities, established a number of international joint labs so as to promote the international scientific and technological cooperation and exchanges[4]. Differing with the vocational education which aims at techniques and skills, the higher education should aim at higher level and deeper academic studies, the international higher education cooperation will extend from undergraduates to the master's degree and then to the doctor's degree, only the teaching and research together are advanced together can the students be qualified for further study and really cultivate high-level talents.

\section{B. Vocational Education Cooperation}

Actually the international cooperation in vocational education is an important part of the international cooperation in higher education, for it has unique teaching characteristics and training objectives, so it is stressed for discussion separately. The training objectives of vocational education mainly aim at skills, which plays an important role in the economic and social development of the countries along the Belt and Road Initiative, and the vocational education is closed to enterprises, which cannot be seen in general higher education. Accordingly during the international cooperation in vocational education, we should pay first attentions to the construction of platforms for technical cooperation and enterprise information exchanges for the countries and regions concerned, which are necessary educational resource for international cooperation in vocational education and also platforms for students to practice and employment. In 2016, representatives of vocational education and enterprises, from 21 countries including China, Sri Lanka, Myanmar along the "Belt and Road Initiative" attended the "Belt and Road Initiative" industry and education collaboration summit held in Beijing, where a consensus was reached finally to jointly set up a "'Belt and Road Initiative" industry and education coordination alliance [5]. That was a good beginning and it has placed a foundation for the international cooperation in vocational education featuring wide scope, better effect and deeper level.

Canada owns advanced experience in vocational education, which can be borrowed for the deep international cooperation in vocational education under the background of Belt and Road Initiative. The vocational education in Canada insists on the principles of cultivating practical talents and setting specialties according to the market demands and giving students adequate time to learn freely. And the students will be granted diplomas as long as they have got the credits as required, before the graduation, the employment guidance center will provide employment service according to the school-enterprise talents agreement and the education of the students of that year. [6] The schoolenterprise cooperation mode and the focuses on the practical teaching in the course system may bring something beneficial for the international cooperation in vocational education under the background of " Belt and Road Initiative". The school-enterprise cooperation mode not only improve students' abilities of practice, bringing more chances for employment, but also benefit the teachers in the vocational colleges, the teachers, in addition to further study in higher education institutions, but also improve the teaching levels through practice in enterprises. It is to not only improve the quality of teachers but also enable students in vocational colleges to get the latest and practical knowledge.

\section{Internet Technology Application and Cooperation at Higher Education Preparation Stage}

The Internet and new technologies can be used to establish relations and exchanges for colleges among different countries. The University of Minerva made use of the Internet to promote the social mechanism, which can be borrowed for us. The four-year undergraduate education of the university is distributed in seven cities around the world including San Francisco, Mumbai, London, Hong Kong and so on, and students in different cities have established cooperation relations with local universities, research institutions and companies, through the cooperation and practice, the students have learned to make use of quality social resources to complete the undergraduate study [7]. The school-running mode of the university is similar to the international education cooperation under the background of Belt and Road Initiative, both introducing external resources to drive the resource allocation reform and management renovation in the university. However, what is to note is that in order to cultivate talents who are truly qualified for all kinds of economic cooperation and cultural exchanges, the international cooperation in higher education or vocational education cannot be carried out only in some country or region for so-call international study, so as far as the cooperation in higher education, the Internet and new technologies are just parts of it, in addition, it is necessary to greatly promote the students of one party or more parties to flow in different countries and regions, learning in flow and developing in practice.

Since the countries or regions develop with different histories and cultures as well as the knowledge and cultural system, the modern educational systems in diverse countries differ seriously, and the students from different countries may not adapt to it immediately when accessing the internationalized higher education, In order to ensure the well going of the international cooperation in higher education, the international education cooperation should be encouraged to extend appropriately to the stages to prepare for higher education or vocational education. For example, for high-school students who are ready for international study, the Internet and new technologies can be fully used, and the students may have access to teaching resources of the targeted countries without leaving home and study 
influenced, which may make preparations for the real international study and improve the competitiveness.

\section{Diverse Participants for Cooperation}

Seen from the participants for international education cooperation, it shall not be limited to the governments, and the global non-governmental organization resources can be fully mobilized to participate in the educational cooperation. Thus it will form a crossed cooperation network between governments, governments and non-governmental organizations, and organizations, and the international education cooperation between non-governmental organizations should establish industrial standards and codes that are accepted by all concerned. For example, the China Education Association for International Exchange, which is highly reputed in the country, is a nationwide organization aiming at private foreign education cooperation and exchange, which was established at the beginning of China's foundation, after about 40-year development, the organization has been exerting unique roles in regulating industrial behaviors, promoting industrial self-discipline and improving the industrial quality. [8] The self-discipline and mutual supervision mechanism in non-governmental organizations are essential for deep international education cooperation in the future. All countries or regions in the cooperation should establish codes of conducts and quality standards that are accepted internationally so as to provide quality guarantee for the international education cooperation.

In addition, the competition of international education market will be more and more intense in the future, and the cooperative education mode will also be varying with the market demand, attracting more enterprises to invest to the international education cooperation. For example, in order to get the advantages in talents, the enterprise circles around the world will make more and more investment to or sponsor the cooperation projects, which will make the cooperative educational institutions be much targeted, besides, more and more cooperative educational institutions will establish cooperation, main cooperation mode include faculty flow, exchange students as well as academic management and exchanges.

\section{CONCLUSION}

More than 2000 years ago, the people living on Eurasia opened an interconnected road relying on diligence and wisdom, through which, the people of all countries conducted a long term trading activities and cultural exchanges. Up to now, peace, development, cooperation and win-win have become themes of the new era, and the ancient road will be revitalized. Education is an important element that is indivisible and penetrating into all aspects of economic cooperation and cultural exchanges among countries, and the international education cooperation is a heart to heart communication between peoples in different countries and an important way to enhance mutual understanding and trust. Under the background of Belt and Road Initiative, to greatly advance the international education cooperation will be bringing more chances and possibilities for the further globally integrated development.

\section{REFERENCES}

[1] Zhang Junrong, Promoting the Upgrade of Belt and Road Initiative Construction with the Host Diplomacy as Chance [N]. Chinese Social Sciences Today, Feb 27, 2017, Period 1155.

[2] Zhang Junrong, Promoting the Upgrade of Belt and Road Initiative Construction with the Host Diplomacy as Chance [N]. Chinese Social Sciences Today, Feb 27, 2017, Period 1155.

[3] [USA] Abraham Flexner, translated by Xu Hui, Chen Xiaofei, Universities-American, English and German [M]. Zhejiang Education Publishing House, Vol.1, 2001, p 4-11.

[4] [USA] Abraham Flexner, translated by Xu Hui, Chen Xiaofei, Universities-American, English and German [M]. Zhejiang Education Publishing House, Vol.1, 2001, p 4-11.

[5] Cross Border Higher Education Quality Guarantee. EB/OL].http://www.cdgdc.edu.cn

[6] Cross Border Higher Education Quality Guarantee .[EB/OL].http://www.cdgdc.edu.cn

[7] Ministry of Education: International Cooperation Joint Lab Program [J] Education, Feb 2014.

[8] Ministry of Education: International Cooperation Joint Lab Program [J] Education, Feb 2014.

[9] Liu Hong, Opportunities, Challenges and Ways for Vocational Education Development in China under the Background of Belt and Road Initiative [J]. Chinese Vocational and Technical Education, 2017(4).

[10] Liu Hong, Opportunities, Challenges and Ways for Vocational Education Development in China under the Background of Belt and Road Initiative [J]. Chinese Vocational and Technical Education, 2017(4).

[11] Jin Yanjun, Enlightenment of Canadian Higher Vocational Education to School Running via International Cooperation [J] Sichuan Cement, 2016(8).

[12] Jin Yanjun, Enlightenment of Canadian Higher Vocational Education to School Running via International Cooperation [J] Sichuan Cement, 2016(8).

[13] Shang Junjie, Cao Peijin, Internet Pushing Universities to NoBoundary Develop [J]. Peking University Education Review, 2017(1)

[14] Shang Junjie, Cao Peijin, Internet Pushing Universities to NoBoundary Develop [J]. Peking University Education Review, 2017(1).

[15] China Education Association for International Exchange [EB/OL].http://www.ceaie.edu.cn/.

[16] China Education Association for International Exchange [EB/OL].http://www.ceaie.edu.cn/. 